\title{
Effect of a Plastic Deformation on the Magnetic Properties of the Fe-31.6\%Mn-6.45\%Si Shape Memory Alloy
}

K. Tamarat, M. Escorne*, A. Percheron-Guegan* and B. Dubois

ISMCM-LISSMA, Material Physics, 3 rue F. Hainaut, 93407 Saint-Ouen, France

* Laboratoire de Chimie Métallurgique et Spectroscopie des terres rares, CNRS, 1 place Aristide Briand, 92195 Meudon cedex, France

\begin{abstract}
Concerning a Fe-Mn-Si shape memory alloy, it was thought of magnetic measurements to follow the evolutions with temperature of an as quenched steel before and after a $2.5 \%$ prestrain.
\end{abstract}

\section{INTRODUCTION}

The shape memory effect, related to the reverse $\varepsilon \rightarrow \gamma$ transformation of a single crystal of Fe$\mathrm{Mn}-\mathrm{Si}$, was first shown by Sato (1). Many works are devoted to polycrystalline Fe-Mn-Si steels $(2,3)$. The $\varepsilon$ phase is grown from large stacking faults in the $\gamma$ austenite. From one hand, silicon decreases both the stacking fault energy and the NEEL temperature. On the other hand, to make a clear distinction between thermal induced martensite $\left(\varepsilon_{\text {th }}\right)$ and the stress induced martensite ( $\varepsilon_{\text {def }}$ ), is not easy. It was thought of the interest of magnetic measurement to precise the differences before and after deformation of an as quenched steel.

\section{ALLOY AND EXPERIMENTAL}

The FM30 alloy was supplied by the "Societé Aubert et Duval", as $18 * 18 \mathrm{~mm}^{2}$ bars swaged and $1373 \mathrm{~K}$ water quenched. The chemical composition ( wt \%) is given in Table 1:

\begin{tabular}{c|l|l|l|l|l}
\hline Fe & $\mathrm{Mn}$ & $\mathrm{Si}$ & $\mathrm{C}$ & $\mathrm{N}$ & $\mathrm{S}$ \\
\hline Balance & 31.6 & 6.45 & 0.018 & 0.0052 & 0.0079 \\
\hline \multicolumn{5}{c}{-Table 1- }
\end{tabular}

Structural and physical characterizations were carried out on the as received alloy called AD1.Details were published elsewhere(4), and the results are summarized in Table 2:

\begin{tabular}{l|l}
\hline $\begin{array}{l}\text { Lattice parameters of the } \\
\text { dual phase alloy } \\
\text { (X-ray diffraction) }\end{array}$ & $\begin{array}{l}\mathrm{a}_{\mathrm{f}}=0,35899 \mathrm{~nm} \\
\mathrm{a}_{\mathcal{E}}=0,25377 \mathrm{~nm} \\
\mathrm{c}_{\mathcal{E}}=0,41452 \mathrm{~nm}\end{array}$ \\
\hline $\begin{array}{c}\text { Magnetic transition } \\
\text { (neutron diffraction) }\end{array}$ & $270<\mathrm{T}_{\mathrm{N}} \gamma<295 \mathrm{~K}$ \\
\hline $\begin{array}{c}\text { Transformation temp. } \\
\text { (elect. resis. meas.). }\end{array}$ & $\begin{array}{c}\mathrm{M}_{\mathrm{S}}=313 \mathrm{~K} \mathrm{~A}_{\mathbf{S}}=411 \mathrm{~K} \\
\mathrm{Af}_{\mathrm{f}}=440 \mathrm{~K}\end{array}$ \\
\hline
\end{tabular}

-Table 2- 
Samples of AD1 ( $3 \mathrm{~mm}$ in diameter and $20 \mathrm{~mm}$ in length) were extended on a Instron machine with a strain rate of $1.710^{-4} \mathrm{~s}^{-1}$. The chosen deformation rate was $\varepsilon=2.5 \%$ as controlled by an extensometer. The appearance of the stress induced martensite did not modified the $X$-ray spectrum of the AD1 alloy (4).Magnetic susceptibility measurements were carried out on the DSM-100 apparatus. Samples were carefully polished in a $\left(\mathrm{HF} / \mathrm{H}_{2} \mathrm{O}_{2}=1 / 15\right)$ solution.A Faraday device was used,with the sample on a silica tube, during heating from 100 to $610 \mathrm{~K}$. Isothermal magnetization curves were recorded under different direct magnetic fields. Then two other temperature ranges were precisely explored (1.4-100K and $298-970 \mathrm{~K}$ )

\section{RESULTS}

1-MAGNETIC SUSCEPTIBILITY BETWEEN 100K AND $610 \mathrm{~K}$.

The results are presented on Fig.1 (for a AD1 sample) and Fig.2.(for a AD1 +2.5\% prestrained sample). The magnetic characteristics are given in Table 3.

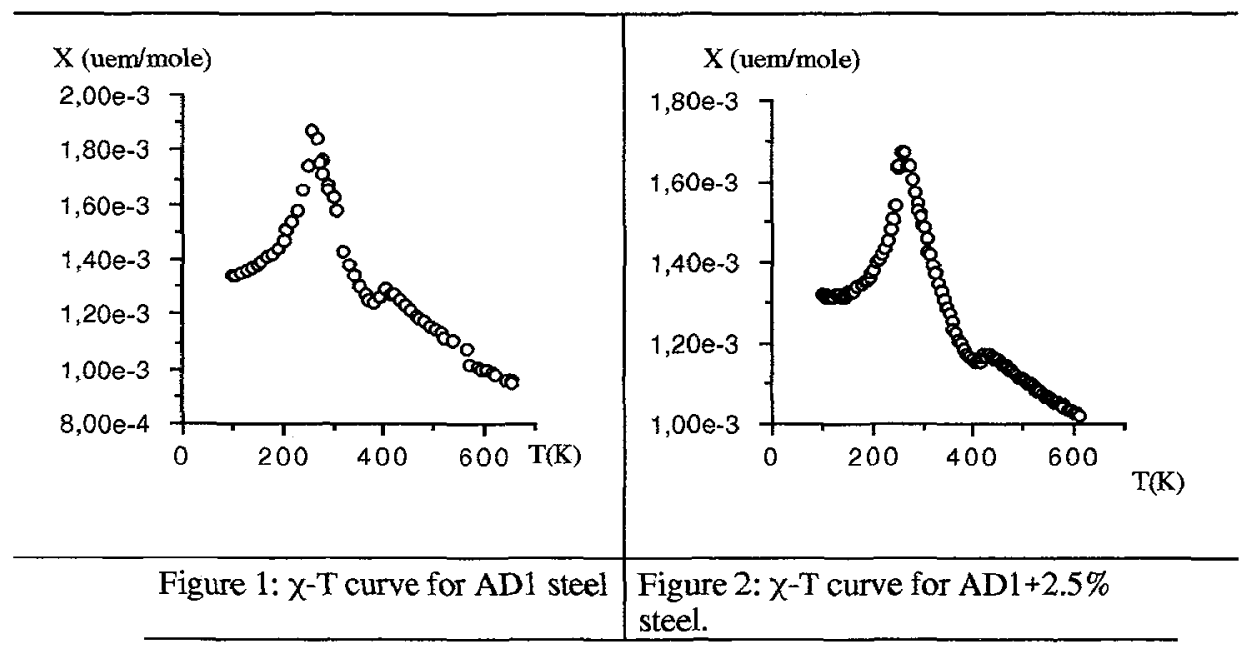

\begin{tabular}{|c|c|}
\hline AD1 steel. & AD1 $+2.5 \%$ steel. \\
\hline $\mathrm{TN}_{\mathrm{N}}=262 \mathrm{~K}$ & $T \mathrm{~N}=260 \mathrm{~K}$ \\
\hline$A_{S}=402 \mathrm{~K}$ & $A_{S}=406 \mathrm{~K}$ \\
\hline$A_{f}=423 K$ & $A f=432 K$ \\
\hline $\begin{array}{l}\left.\chi_{0}=0 \text { (uem } / \text { mole }\right) \\
C=0589(\text { um } / \text { mole } \mathrm{K}\end{array}$ & $\begin{array}{l}\left.\chi_{0}=0 \text { (uem } / \text { mole }\right) \\
C=0.422(\text { uem } / \text { mole) } \mathrm{K}\end{array}$ \\
\hline$\Theta=-42.85 \mathrm{~K}$ & $\Theta=-86.11 \mathrm{~K}$ \\
\hline$n_{\text {eff }}=2.17 \mu \mathrm{B}$ & $n_{\text {eff }}=1.94 \mu \mathrm{B}$ \\
\hline
\end{tabular}

First of all, a decrease of the magnetic susceptibility with the applied stress is observed.

However, the NEEL temperature is not much modified by the prestrain. An increase of $9 \mathrm{~K}$ of the Af temperature is a normal phenomenon. The second set of values of Table 3 deals with the application of the CURIE-WEISS law:

$$
x=\chi_{0}+\frac{C}{T-\Theta}
$$


where $\Theta$ is a constant, characteristic of the alloy ,and C is the CURIE constant, varying with the thermal treatement. The average effective magnetic moment by atom ( neff) was calculated from:

$$
\mathrm{n}_{\mathrm{eff}}=\sqrt{7.995 \times \mathrm{C}}
$$

If the NEEL temperature is not strongly modified, the changes in the $C, \Theta$ and $n_{e f f}$ values indicate a variation in the magnetic structure after prestrain. The antiferromagnetic $\gamma$ phase shows a $28 \%$ decrease of the CURIE constant and of $10 \%$ of the number of carriers. These phenomena were no more studied in this work. In order to look for the magnetic nature of the $\varepsilon$ phases, experiments were carried out at lower temperatures.

\section{2-MAGNETIZATION MEASUREMENTS BETWEEN 1.4K AND IOOK.}

The $\chi(T)$ curves are shown in Fig 3: some effects appeared between 20 and $90 \mathrm{~K}$ and it was thought of a change of the magnetic nature of $\varepsilon$ phases. Below $20 \mathrm{~K}$, the regular increase of the susceptibility was treated by relation (I) with $\chi 0=1.3310^{-3}$ and $1.3810^{-3}$ (uem/mole) for AD1 and for AD1+2.5\% samples respectively. The results are given in Table 4: from the sign of $\Theta$, it is believed that both $\varepsilon$ martensites are antiferromagnetic phases. In the case of $\mathrm{AD} 1+2.5 \%$ steel, this assumption is supported by the " field cool" curves shown in Fig 4: the isothermal magnetization curves are a linear function $(\mathrm{I}=\mathrm{a} \mathrm{H}$ ) of the magnetic field. Also, we think of the susceptibility fluctuations ( Fig 3 ) are related to a para-antiferromagnetic transition in the 90-20K temperature range.

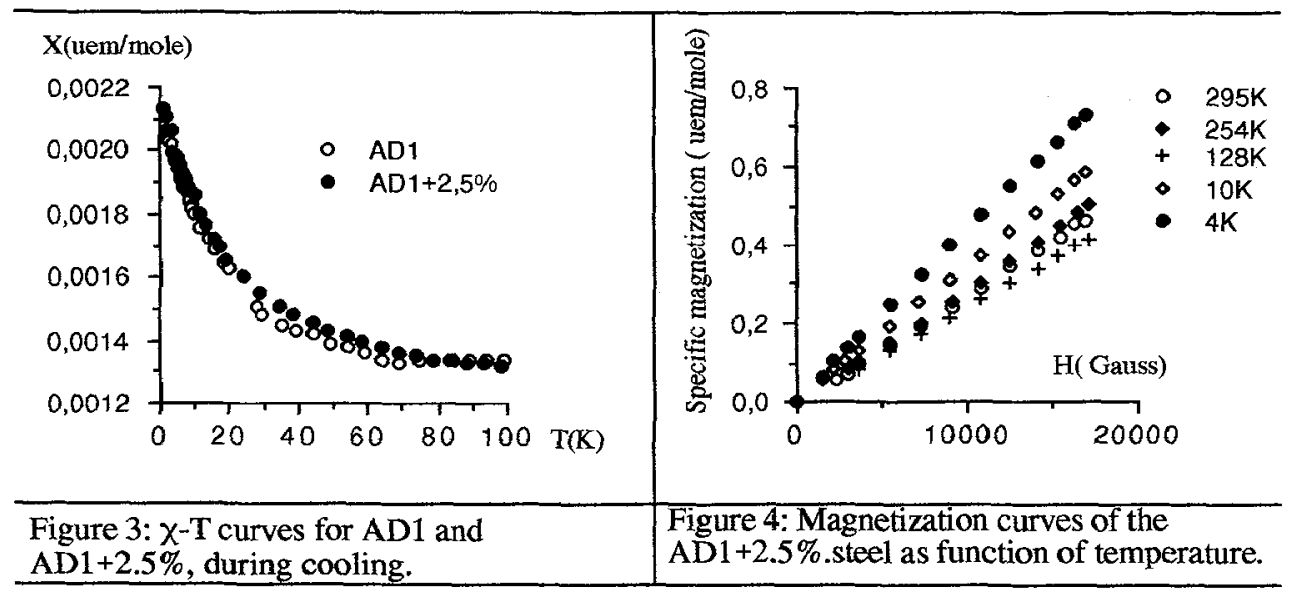

\begin{tabular}{l|l}
\hline \multicolumn{1}{c|}{ AD1 steel. } & \multicolumn{1}{c}{ AD1+2.5\% steel. } \\
\hline$\chi 0=1.3310^{-3}$ (uem/mole) & $\chi_{0}=1.3810^{-3}$ (uem $/$ mole) \\
$C=0.00797$ (uem/mole).K & $C=0.0156$ (uem $/$ mole).K \\
$\Theta=-7.54 \mathrm{~K}$ & $\Theta=-19 \mathrm{~K}$ \\
$\mathrm{neff}_{\mathrm{e}}=0.25 \mu \mathrm{B}$ & $\mathrm{n}_{\mathrm{eff}}=0.35 \mu \mathrm{B}$ \\
$\mathrm{Tx}=60 \mathrm{~K}$ & $\mathrm{~T}_{\mathrm{X}}=90 \mathrm{~K}$ \\
\hline
\end{tabular}


From Fig 3, the upper curve, corresponding to the widest volume of $\varepsilon$ martensite, yields the highest number of average effective carriers. Comparing Table 4 to Table 3 , it is interesting to note the decrease of the C constant, related to the temperature effect, particularly for the AD1 steel. To complete this study, attention was paid to the susceptibility variations during heating up to $970 \mathrm{~K}$, before cooling.

\section{3-SUSCEPTIBILITY VARIATIONS DURING $R T \rightarrow 970 K \rightarrow R T$ CYCLE OF THE ADI+2.5\% PRESTRAIN SAMPLE.}

Results are shown on the Fig 5 ( for heating) and Fig 6 ( for cooling). On Fig 5, the reverse transformation temperatures are well observed, with $A_{s}=422 \mathrm{~K}$ and $A_{f}=472 \mathrm{~K}$. However, the main fact is an increase of the susceptibility at about $700 \mathrm{~K}$ with a shouldering effect around $830 \mathrm{~K}$.

During cooling, a strong increasing of the susceptibility was noted when the temperature decreases and equation (I) indicates the presence of ferromagnetic phases. A characteristic magnetization curve was recorded at room temperature (Fig 7).

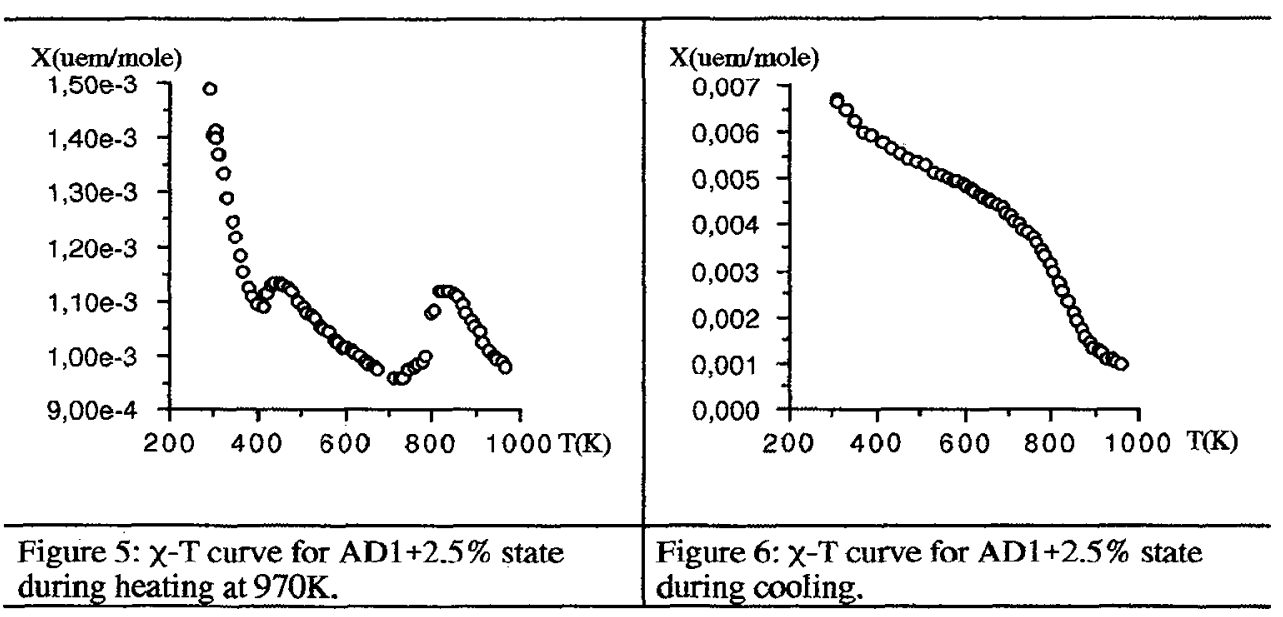

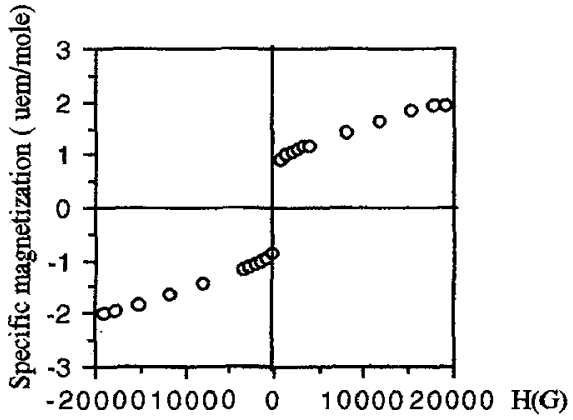

Fig 7: Magnetization curve at room temperature. 


\section{DISCUSSION}

First of all, in the 100-610K temperature range, there is no noticeable change in the NEEL temperature of the $\gamma$ austenite after a $2.5 \%$ prestrain of the studied alloy. This results are in agreement with those obtained by neutron diffraction (4) The stress induced $\varepsilon$ martensite influences more the $\Theta$ and $C$ constants of the CURIE-WEISS law, rather than the NEEL temperature. From these magnetic susceptibility measurements, the $\mathrm{Af}_{\mathrm{f}}$ temperature appears slightly more increased than the As temperature.

About the magnetic moment, we noted that iron is the basis of the alloy. However, antiferromagnetic iron has a moment $\mu=0.7 \mu \mathrm{B}$ below $80 \mathrm{~K}$ (5). In an Fe30Mn alloy, an average effective number of carriers of $1.94 \mu \mathrm{B}$ was indicated (6).In substituted manganese stainless steels, LEDBETTER et al (7) claim that manganese atoms were likely the carriers. The values we found are in the same magnitude order than those published but we cannot go further now.

Between 20 and $90 \mathrm{~K}$, it is believed that the the susceptibility fluctuations with temperature are typical of the appearance of the antiferromagnetism of the $\varepsilon$ martensites. The magnetization curves at different temperatures ( field $\mathrm{cool}$ ) indicates the absence of mictomagnetism (9) . For the AD1+2.5\% strain steel, our results could be compared to those of OHNO et al (10) for heavily cold worked Fe-(18-30)at\% Mn alloys. They found $n_{e f f}=0,25 \mu \mathrm{B}$ and $T_{N}{ }^{\varepsilon}=230 \mathrm{~K}$. The value of $n_{e f f}=0,35 \mu \mathrm{B}$ is not very different but the fact that $20<\mathrm{TN}^{\varepsilon}<90 \mathrm{~K}$ is a clear effect of the silicon content. During heating at $970 \mathrm{~K}$, a shouldering effect was observed after the As-Af temperatures range. It is belived that this result is associated with the multivariance phenomena as detected by dilatometry and detailed elsewhere (10). The restacking is associated to the stresses relaxation in the $2.5 \%$ prestrain specimen. Decreasing the temperature from $970 \mathrm{~K}$, increases drastically the susceptibility. The appearance of ferromagnetic phases due to silicon influence and oxygen pollution has to be taken in account. At room temperature, after the experiment, the oxided sample was found ferromagnetic (Fig.7).

\section{CONCLUSIONS}

1-The NEEL temperature is not really affected by a 2.5\% prestrain in FM30 steel.

2-Between 20 and $90 \mathrm{~K}$, it was thought of the antiferromagnetism of the martensites, but the thermal induced and stress induced $\varepsilon$ martensites are not clearly differentiated.

3- During heating, the multivariance effect is detected by susceptibility measurements.

4- Ferromagnetic phases appear during cooling from $970 \mathrm{~K}$ to R.T.

\section{REFERENCES}

(1) A.Sato, K.Soma, E.Chishima et T.Mori, Acta. Met., 30, (1982), 1177-1183

(2) M.Murakami, H.Otsuka, H.G.Suzuki, and S.Matsuda, Proc.I.C.O.M.A.T. (1986), 985-990.

(3) J.S.Robinson, P.G.MacCormick, Mat.Sci.Forum, Proc.I.C.O.M.A.T., Vol 56 ( 1990) 649-653.

(4) K.Tamarat, G.André, B.Dubois, Proc.I.C.O.M.A.T.92, Monterey, 1994,1181-1186 
(5) R.J.Weiss, Proc.Phys.Soc., Vol 28,(1963),281-288.

(6) Y.Endoh, Y.Ishikawa, J.Phys.Soc.Jpn.,30,(1971),1614-1627.

(7) H.M.Ledbetter, E.W.Collings, Proc.107th A.I.M.E., (1978), 22-40.

(8) E.W.Collings, R.L.Cappeletti, Cryogenics, 25 (1985) 713-718

(9) H.Ohno, M.Mekata, J.Phys.Soc.Jpn.,31, Nº 1,(1971),102-108.

(10) K.Tamarat, G.Cizeron, T.Bouraoui, J.Papier, B.Dubois, ESOMAT Conf. B'A (1994). 